\title{
The methodology for choosing solutions by developing an optimal topology of power supply system
}

\author{
Olga Svezhentseva ${ }^{1}$, Marina Umnova $^{1}$
}

${ }^{1}$ Federal State Budget Educational Institution of Higher Education «Irkutsk National Research Technical University», 664074, Irkutsk, st. Lermontov, 83

\begin{abstract}
Annotation. The development of the optimal topology of power supply systems for various purposes is an intractable problem that cannot be formalized as a single task. This problem can be considered as a complex of tasks having a hierarchical structure - the hierarchy is present both at the functional and at the territorial levels. The main typical tasks arising in the process of developing of the optimal topology of the power supply system in a city microdistrict are highlighted, a formal statement of tasks is given, methods for their solution are proposed and demonstrated. Approaches to solving typical problems are built on the theory of combinatorial analysis, methods of heuristic modeling, genetic programming, methods for solving optimization problems on graphs.
\end{abstract}

\section{Introduction}

In this article a complex of optimization problems for solutions to justify the development of power supply systems in cities is considered which is a hierarchical model consisting of three stages (functional levels). The graphical interpretation of the model is shown in Fig. 1.

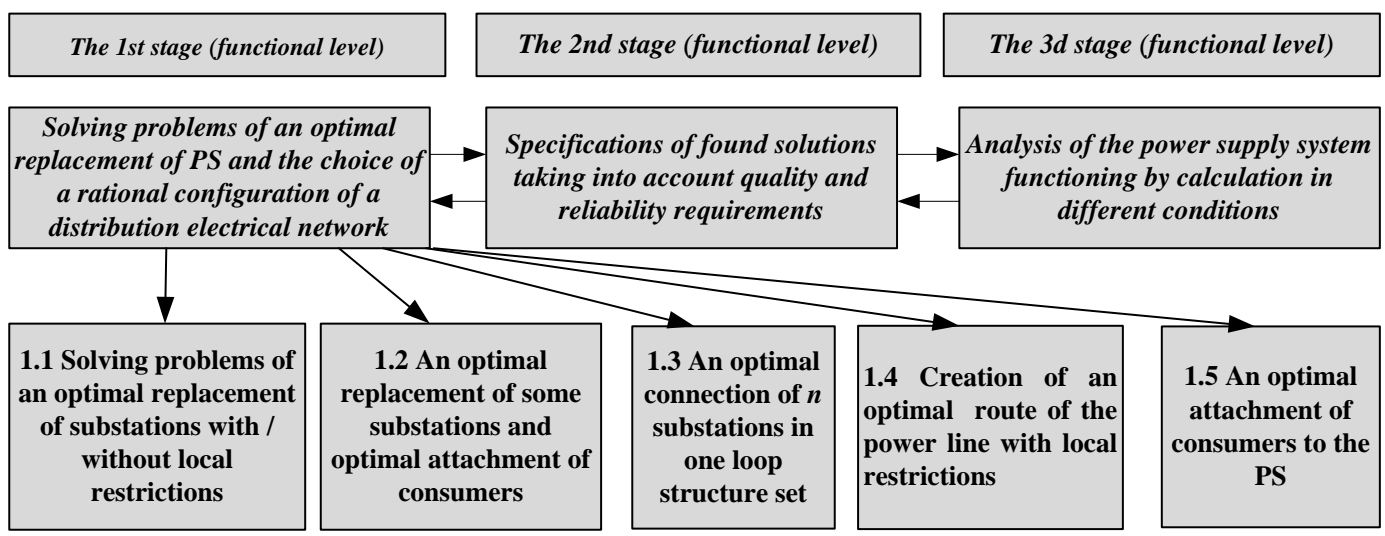

Fig.1: Hierarchical model to justify the development of power supply systems of cities

The first stage is the solution of a set of related tasks for creating a rational configuration of a distribution electrical network, each of the tasks listed at this stage can have different mathematical and substantial formulations depending on the type of electrical network, the presence of various types of restrictions, the number of power sources placed (PS), requirements for optimal connection of consumers to power supply sources, etc.

The 2nd stage of the hierarchical model considered in this article is the solution of tasks to refine the found solutions, taking into account the requirements for quality and reliability. The issue of taking into account restrictions on permissible voltage losses (deviations) is relevant for distribution networks of $20 \mathrm{kV}$ and lower [1].

The problem of ensuring a reliable power supply is a task of purposeful activity in an artificially created system, therefore it can be attributed to a management task [2]. The main methodological means of ensuring reliability can be a systematic approach, which allows to represent the considered problem which is very complex and diverse as a system of subtasks, i.e. apply the principle of decomposition - breaking down a big problem into simpler parts - elements.

The reliability of the system is determined not only by the strength of the structures of the materials from which the elements are made, but also by how the elements of the system are generally structured [8]. The electrical network can be built in a ring-shaped, radial or mixed scheme, etc. In all these variants of the network, its reliability is different. This follows from the well-known position that the structure of an object largely determines its properties. Consequently, structuring the system directed in a certain way during its creation is also a means of ensuring reliability. 
At the $3 d$ stage, various modes of operation of the power supply system are calculated. Determination of indicators of various modes of electrical networks is of independent importance in order to check the admissibility of the equipment operating conditions and to ensure the required voltage quality, and is also necessary to solve more complex problems (for example, by calculating electricity losses, optimizing modes, etc.) [3].

Usually, the calculation of the distribution network mode consists in determining the powers or currents in the sections of the electrical network and the voltages in its nodes. The found currents are used to check the admissibility of the mode under the conditions of heating the conductors.

The calculation of the network is carried out starting from the most distant section, in the direction of the power source.

\section{A set of tasks for creation the optimal configuration of power supply systems for cities, depending on territorial affiliation}

For the electric networks of a city microdistric the following territorial, hierarchical structure of the power supply system, depending on the voltage levels, described in the source $[2,4]$ is proposed.

In this case, a hierarchical system is a system with a multilevel structure, the elements of which are arranged by levels in order from the highest to the lowest level, i.e. in the order of subordination.

We give a description of the tasks of the 1st stage of the hierarchical approach considered above to substantiate the development of power supply systems in cities depending on the territorial levels (table 1).

Table 1. Formalization of tasks to be solved depending on the territorial levels of the city power supply system

\begin{tabular}{|c|c|}
\hline Territorial levels & The tasks to be solved \\
\hline $\begin{array}{c}\text { The 1st territorial } \\
\text { level. } \\
\text { Power sources: } \\
\text { electric power } \\
\text { systems (EPS); } \\
\text { Consumers: step- } \\
\text { down substations } \\
\text { at the of voltage } \\
35 \text { - } 220 \mathrm{kV} \text { and } \\
\text { higher; } \\
\text { Networks: at the } \\
\text { voltage of } 35 \text { - } \\
220 \mathrm{kV} \text { and } \\
\text { higher }\end{array}$ & $\begin{array}{l}\text { 1. optimization of connection of } \\
\text { consumers to several PS } \\
\text { 2. optimization of the laying of the } \\
\text { power transmission line connecting } \\
\text { the consumer with the PS, taking into } \\
\text { account the local restrictions, } \\
3 \text {. optimization of the connection of } \\
\text { the elements of the power supply } \\
\text { system into a circuit of a certain } \\
\text { structure. }\end{array}$ \\
\hline $\begin{array}{l}\text { The } 2^{\text {nd }} \text { territorial } \\
\text { level. } \\
\text { Power sources: } \\
\text { step-down } \\
\text { substations at the } \\
\text { voltage of } 35- \\
220 \text { kV and } \\
\text { higher; } \\
\text { Consumers: } \\
\text { distribution points } \\
\text { for the voltage of } \\
6-10 \mathrm{kV} \text {; } \\
\text { Networks: at the } \\
\text { voltage of 6-10 } \\
\mathrm{kV} \text {. }\end{array}$ & $\begin{array}{l}\text { 1. optimization of the location of one } \\
\text { PS with and without regard to local } \\
\text { restrictions, } \\
\text { 2. optimization of connection of } \\
\text { consumers to several PS } \\
\text { 3. optimization the placement of } \\
\text { several PS and attaching consumers to } \\
\text { them, } \\
\text { 4. optimization of the laying of the } \\
\text { power transmission line connecting the } \\
\text { consumer with the PS, taking into } \\
\text { account the local restrictions, } \\
5 \text {. optimization of the connection of } \\
\text { the elements of the power supply } \\
\text { system into a circuit of a certain } \\
\text { structure. }\end{array}$ \\
\hline
\end{tabular}

\begin{tabular}{|c|c|}
\hline $\begin{array}{l}\text { The } 3 \text { d territorial } \\
\text { level. } \\
\text { Power sources: } \\
\text { distribution points } \\
\text { at voltage of } 6- \\
10 \mathrm{kV} \text {; } \\
\text { Consumers: } \\
\text { transformer } \\
\text { substations at } \\
\text { voltage of } 6-10 \text { / } \\
0.4 \mathrm{kV} \text {; } \\
\text { Networks: at a } \\
\text { voltage of } 6-10 \\
\mathrm{kV} \text {. }\end{array}$ & $\begin{array}{l}\text { 1. optimization of the location of one } \\
\text { PS with and without taking into } \\
\text { account local restrictions, } \\
\text { 2. optimization of connection of } \\
\text { consumers to several PS, } \\
3 \text {. optimization the placement of } \\
\text { several PS and attaching consumers to } \\
\text { them, } \\
4 \text {. optimization of laying a power } \\
\text { transmission line at the voltage of } 6-10 \\
\mathrm{kV} \text {, connecting the consumer with the } \\
\text { PS taking into account local } \\
\text { restrictions, } 5 \text { optimization of the connection of } \\
\text { the elements of the power supply } \\
\text { system into a circuit of a certain } \\
\text { structure. }\end{array}$ \\
\hline $\begin{array}{l}\text { The } 4^{\text {th }} \text { territorial } \\
\text { level. } \\
\text { Power supplies: } \\
6-10 \text {, } 0.4 \mathrm{kV} \\
\text { transformer } \\
\text { substations; } \\
\text { Consumers: } \\
\text { consumers } \\
\text { themselves; } \\
\text { Networks: at the } \\
\text { voltage of } 0.4 \mathrm{kV} \text {. }\end{array}$ & $\begin{array}{l}\text { 1. optimization of the location of one } \\
\text { transformer substations; with and } \\
\text { without taking into account the local } \\
\text { restrictions, } \\
2 \text {. optimization of connection of } \\
\text { consumers to several PS } \\
\text { 3. optimization of the placement of } \\
\text { several PS and attaching consumers to } \\
\text { them, } \\
4 \text {. optimization of the laying of a } \\
\text { power transmission line at the voltage } \\
\text { of } 0.4 \mathrm{kV} \text {, connecting the consumer } \\
\text { with the PS, taking into account the } \\
\text { local restrictions } \\
5 \text {. optimization of the connection of } \\
\text { the elements of the power supply } \\
\text { system into a circuit of a certain } \\
\text { structure. }\end{array}$ \\
\hline
\end{tabular}

After analyzing the composition and functional assignment of individual elements of each level of the power supply system the following conclusions can be drawn:

1. At each territorial level it is possible to distinguish elements that play the role of power sources, as well as elements that play the role of consumers, and at the next territorial levels consumers from the previous level can play the role of power sources;

2 . One can define two ways for connection of the power source to the consumer of electrical power $((x, y)-$ are the coordinates of the PS, $\left(x_{1}, y_{1}\right)-$ are the coordinates of the consumer, $l_{1}-$ is the distance from the PS to the consumer), the first method - on the territory of the projected object there are no restrictions in the form of a rectangular grid of transits, the second method is a line connecting the consumer with the PS runs parallel to the coordinate axes.

3 . There are various ways of connecting elements in a circuit of a certain structure.

a) a circuit of the radial structure,

b) a circuit of the main structure,

c) a loop circuit,

d) a ring circuit, etc.

The tasks of creating a rational configuration of the power supply system of the city microdistrict must be solved at all territorial levels of the above structure.

We consider the main formulations of problems and the proposed methods for their solution. 


\subsection{The problem of the optimal attaching of consumers to PS}

This problem is a classical combinatorial problem - it is determining the number of ways to place some objects in a certain number of boxes so that the specified constraints are met [5]. Formally, this problem can be formulated as follows: sets $X, Y$ are given, and $|X|=m,|Y|=n$ here $|X|$ is the cardinality of the set $X$, i.e. the number of its elements. How many functions are there that satisfy the given constraints? The elements of the set $X$ correspond to the objects, the elements of the set $Y$ correspond to the boxes, and each function $f: X \rightarrow Y$ defines some placement, indicating for each object $x \in X$ the box $f(x) \in Y$ in which our object is located.

From this set of functions, one needs to choose one that provides the minimum of an objective function of the form

$$
\min \sum_{i=1}^{k} \sum_{j \in B} C_{i . j}
$$

Here $C_{i . j}$ are the costs for transmission of electricity from the the $i-$ PS to the the $j_{-}$consumer located in the that block of a particular partition. It is assumed that this cost function is proportional to the transmitted power and the distance from the consumer to the power supply.

This problem belongs to the class of intractable problems. To solve this problem, it is proposed to use the following heuristic algorithm:

1. we arrange the powers of consumers in descending order $S_{1} \geq S_{2} \geq \ldots \geq S_{n}$. We will also arrange the cardinalities of the PS used for this variant of the problem in descending order $S_{P S}^{1} \geq S_{P S}^{2} \ldots . S_{P S}^{6}$

2. $L=1$

3. We fix the $L$ consumer for the PS while simultaneously fulfilling two conditions: a) the shortest distance from the consumer to the PS; b) the total capacity of consumers attached to PS does not exceed its power. If there are several PS for which both of these conditions will be met, then we choose the PS with the lowest power. Here, speaking about the power of the PS, we consider this value not constant, but changing dynamically during the working of the algorithm; we assume that the power of the PS at the moment of time $t$ is the power of the PS minus the total power of the consumers attached to this PS at this stage of the algorithm execution.

4. We take $L=L+1$. If $L>n$ then stop in program execution, otherwise go to step 3 . Heuristics used in the construction of this algorithm.

- By streamlining the weights of consumers, the effect of "first attachment of the largest consumers" is achieved, while the restrictions on free capacities of PS are not so strong.

- By attaching other things being equal, the consumer for the PS with the lowest capacity, the effect of "the fastest attachment of consumers for the PS of lower capacity" is achieved, since it is more difficult for these PS to select combinations of consumer capacities to cover the PS capacity.

\subsection{The problem of optimal placement of several PS and attaching consumers to them in the power supply system}

The problem of the optimal placement of several power sources in the power supply system (the excess number of places for possible placement of PS is indicated) and the rational attachment of electric power consumers to them. In this formulation, it becomes necessary to solve repeatedly the problem of optimal attachment of consumers to fixed power supplies. This is necessary to calculate the objective function for each possible solution to the problem. In terms of content, this formulation of the problem also indirectly takes into account the limitations of the general plan on the choice of the PS location: an excess number of places for the PS location is indicated (these points are searched on the general plan of the designed object, taking into account the area allocated for the PS installation), the number of such places can be quite large as a rule, these points should cover the entire area of the designed object.

This, more general task consists of the following series of subtasks:

- selection of standard sizes of power supplies from the proposed standard range;

- selection of the location of individual power supplies;

- rational attachment of electric power consumers to power sources.

It is required to choose the most economical variant for placing PS taking into account the costs of delivering electricity to consumers, and the following parameters should be selected optimally:

- a variant $i$ of the many possible combinations of the number and standard sizes of power supplies $L=\{1,2, \ldots, l\}$;

- location of power supplies from the proposed $m$ possible locations;

- to determine for each consumer which power source will be attached to.

To solve the optimization problem, the genetic algorithm was developed, maximally adapted to the specifics of the problem being solved $[6,7,8]$. At the same time its following components and procedures were developed:

1. the ways of coding possible solutions for two cases of the same standard sizes of the used PS and different standard sizes of the used PS;

2. an algorithm for creating an initial population, taking into account all the genetic material of the problem (all possible locations for the PS, all standard sizes of sources of electrical power);

3. the algorithm of the crossing operation for the case of the same standard sizes of power supplies;

4. the algorithm of the crossing operation for the case of different standard sizes of power supplies;

5. the algorithm for calculating the objective function based on an effective heuristic algorithm for attaching consumers to power supplies;

6. the developed algorithms are realized as programs in the embedded programming language of the MATLAB system. 
Here is the result of a test calculation according to the developed program (Fig. 2,3). The task was to attach 51 consumers on the general plan of a residential microdistrict for 8 transformer substations, the excess number of possible transformer substations locations ( 15 places) in a given territory was indicated.

The best value of the objective function for the given parameters of the genetic algorithm: $1.0000 \mathrm{e}+000$ $7.5693 \mathrm{e}+005$

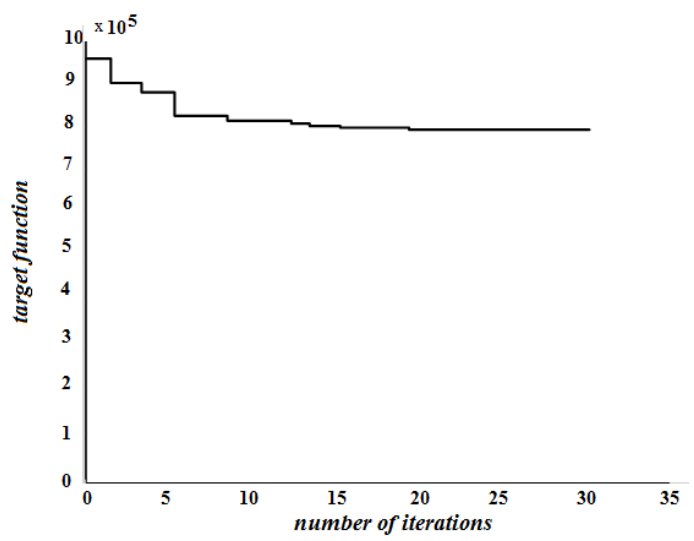

Fig. 2. Graph of changes in the objective function (number of individuals $=500$, number of iterations $=$ $100, S_{P S}=1100 \mathrm{kVA}$ first 30 iterations)

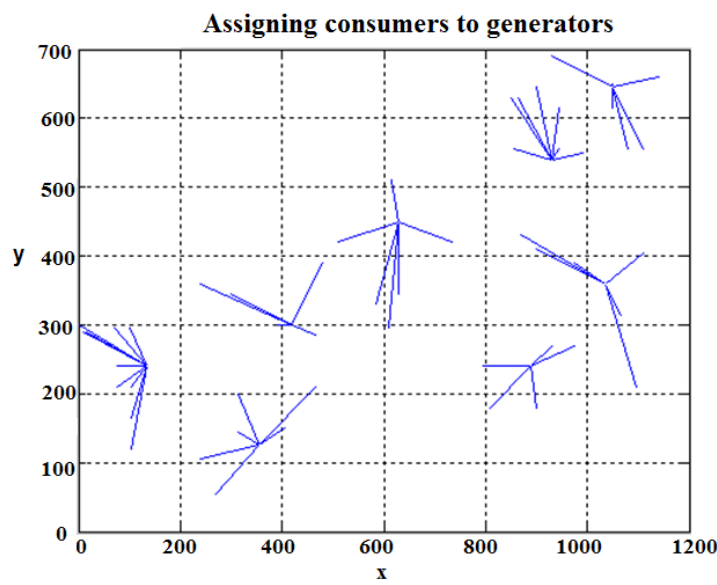

Fig. 3. Result output screen: Optimal attaching of consumers (number of individuals $=500$, number of iterations $=100$, ) $100, S_{P S}=1100 \mathrm{kVA}$

\subsection{The problem of optimal choice of the configuration of the electric distribution network of the loop structure}

In power supply systems, there are three main types of power supply (radial, ring, arterial) and four main types of network structure: radial, arterial, ring, loop.

The loop network is used in urban distribution networks to supply consumers of the second and third categories of reliability. When creating a loop structure, the problem of the optimal connection $n$ of transformer substations into a loop network diagram arises. Each of the substations $n$ has its own location. We number the substations $i=1, \ldots, n$. For each of these substations, we set the coordinates of their location $\left(x_{i}, y_{i}\right), \quad i=\overline{1, n}$. The task is to connect these substations according to the type of a loop circuit: two dead-end transformer substations have connections only with any one substation of this group, all the others are connected to two substations, that is, from the point of view of the mathematical theory of graphs, the degree of each vertex forming a graph, should not exceed 2 (it is assumed that the number of transformer substations in the group is more than two $n>2$, otherwise the task is meaningless).

This problem is one of the modifications of the problem of finding the shortest skeleton on a given graph. Let $G(V, E)$ it be a graph, here $V$ is the set of vertices of the graph, $E$ is the set of edges of the graph. A spanning subgraph of a graph is a subgraph containing all the vertices of the original graph. A spanning subgraph that is a graph called a skeleton. If we set the lengths of the edges, then we can pose an optimization problem about finding the shortest skeleton. We modify the well-known Kruskal algorithm in relation to the solution of this problem [10]. Input: a graph $G(V, E)$ given by a list $E$ of edges of a graph $G$ with lengths.

1. Put the required graph $T=\varnothing$ the graph is given by the set of edges .

2. Order edges $E$ in ascending order of lengths.

3. For $i=\overline{1,(p-1)}$

4. $k:=1$ nnumber of the considered edge\}

5. While adding an edge $E(k)$ a cycle $T$ is formed or the degree $\forall$ of the vertex $\mathrm{V}$ is equal to 3 , then put $k:=k+1$ skip the edge $E(k)$ \}.

6. The end of the loop with a precondition.

7. $T:=T \bigcup\{E(k)\}$ add this edge to SST $\}$

8. End of cycle by $i$.

9. Output: set of $T$ edges of the shortest skeleton An example of the realization of this algorithm.

The initial data required to determine the lengths of the edges of the graph are given in table. 2 .

Table 2. The coordinates of transformer substations' location

\begin{tabular}{|c|c|c|}
\hline $\begin{array}{l}\text { The transformer substations' } \\
\text { (TS)item }\end{array}$ & $\begin{array}{l}\text { Coordinate } \\
\text { X } \mathrm{m} \text {. }\end{array}$ & $\begin{array}{l}\text { Coordinate } \\
\text { У }\end{array}$ \\
\hline TS 1 & $\mathrm{X} 1=355$ & $Y 1=125$ \\
\hline TS 2 & $X 2=420$ & $\mathrm{Y} 2=300$ \\
\hline TS 3 & $X 3=630$ & $Y 3=450$ \\
\hline TS 4 & $\mathrm{X} 4=1035$ & $Y 4=360$ \\
\hline TS 5 & $X 5=1050$ & $Y 5=645$ \\
\hline TS 6 & $X 6=930$ & $Y 6=540$ \\
\hline TS 7 & $X 7=135$ & $\mathrm{Y} 7=240$ \\
\hline TS 8 & $X 8=890$ & $Y 8=240$ \\
\hline
\end{tabular}

The result of the program, according to the proposed algorithm for the initial data (Table 3 ) is presented in Table 6.

Table 3. The result of the program

\begin{tabular}{|l|l|l|l|l|}
\hline $\begin{array}{l}\text { Edge starting } \\
\text { vertex number }\end{array}$ & $\begin{array}{l}\text { Edge ending } \\
\text { vertex } \\
\text { number }\end{array}$ & $\begin{array}{l}\text { Edge } \\
\text { weight }\end{array}$ & $\begin{array}{l}\text { Start } \\
\text { vertex } \\
\text { degree }\end{array}$ & $\begin{array}{l}\text { End } \\
\text { vertex } \\
\text { degree }\end{array}$ \\
\hline 5 & 6 & 159 & 1 & 1 \\
\hline 1 & 2 & 186 & 1 & 1 \\
\hline 4 & 8 & 188 & 1 & 1 \\
\hline 4 & 6 & 208 & 2 & 2 \\
\hline
\end{tabular}




\begin{tabular}{|l|l|l|l|l|}
\hline 1 & 7 & 248 & 2 & 1 \\
\hline 2 & 3 & 258 & 2 & 1 \\
\hline 3 & 8 & 334 & 2 & 2 \\
\hline
\end{tabular}

2.4 The problem of optimal laying of the line connecting the consumer with the PS, taking into account the local restrictions

The shortest path problem is the problem of finding the shortest path between two vertices of a connected undirected graph. It belongs to the class of graph optimization problems. We show the formulation of the problem and its solution using the Floyd's algorithm using the example of solving the problem of constructing an optimal power line route.

It is necessary to select on the local map the route of the power line between the two peaks. The generally accepted criterion for the optimality of a transmission line is the minimum of the reduced costs $C$ for the construction and operation of such a network. Obviously, for given specific reduced costs (for given brands of conductors and given cross-sections), the cost of a power transmission line will be the lowest when the starting and ending vertices are connected by a straight line. However, on a straight-line route, there may be different types of area (arable land, meadow, swamp, hills, etc.). Obviously, the cost of $1 \mathrm{~km}$ of the line will vary depending on the type and relief of the area. For example, laying a route in a forest is more expensive than in a meadow. Therefore, it may be advisable to take the route longer, avoiding high line cost sections. Moreover there are irresistible area obstacles (water bodies, rocks, airfields, etc.) that the projected route must bypass.

We give a formal mathematical formulation of the considered problem [10]. Let an undirected graph $G(X, U)$ be given, where $X-$ is the set of vertices of the graph, $U-$ is the set of graph arcs. All points located on the boundaries of the zones are selected as the vertices of the graph, plus two points representing the starting and ending vertices. We introduce the notation:

$x_{0}-$ starting vertex,

$x_{k}-$ ending vertex,

$x_{1}^{1}, x_{2}^{1}, \ldots x_{n 1}^{1}-$ points located on the border of the 1 st zone

$x_{1}^{2}, x_{2}^{2}, \ldots x_{n 2}^{2}-$ points located on the border of the 2 nd zone

$x_{1}^{k}, x_{2}^{k}, \ldots x_{n k}^{k}-$ points located on the border of the $\mathrm{k}$-th zone

$k$-the number of zones into which the area is divided.

Thus, the number of vertices in the graph is equal to $M=n_{1}+n_{2}+\ldots+n_{k}+2$. The number of arcs in the original graph is determined by the connectivity matrix. We compare to each arc of the original graph a weight function equal to the value of the reduced costs for the construction and operation of the corresponding section of the power transmission line.
Summarizing all of the above, this graph can be represented as a matrix of weights $\mathrm{V}$ with dimensions $(M \times M)$ :

$V(i . j)$ $=\left\{\begin{array}{l}0, \text { for } i=j \\ \text { Vij. final value if there is an arc from } i \text { into } j \\ \infty, \text { if there is no arc } i \text { into } j\end{array}\right.$

where $\mathrm{V}_{\mathrm{ij}}=\mathrm{C}_{\mathrm{ij}}$ are the reduced costs for the construction and operation of the corresponding section of the line.

It is proposed to solve the problem formulated above using Floyd's algorithm.

\section{Conclusions}

The legitimacy of using a hierarchical approach to solving a complex of problems to justify the development of power supply systems for various purposes. The problem is built into this complex as an integral part of the problem of synthesizing the optimal topology of the electrical network, which consists of a number of typical subtasks. Various approaches to solving these typical subtasks are demonstrated. They are based on the theory of combinatorial analysis, methods of heuristic modeling, genetic programming, methods for solving optimization problems on graphs.

\section{References}

1. Gerasimenko, A.A. Transmission and distribution of electrical energy / A.A. Gerasimenko, V.T. Fedin, Rostov n / D: Phenix, 2006 .- 718 p.

2. Voropai, N.I. System theory for electric power engineers / N.I. Voropai M .: Nauka, 2000 .- 272 p.

3. Kudrin, B.I. Power supply of industrial enterprises / B.I. Kudrin. - M .: "Interment Engineering", 2006. - 670 p.

4. Voropai, N.I. Hierarchical modeling in substantiating the development of electric power systems / N.I. Voropay // ExponentaPro. Mathematics in applications. - 2003. - №4. - P. 24 - 27.

5. Svezhentseva, O. V. Heuristic algorithms for the optimal fixation of a multitude of consumers for power sources // All-Russian scientific and practical conference "Increasing the efficiency of production and use of energy in Siberia", Irkutsk: IrGTU, 2007.

6. Voropay N.I., Svezhentseva O.V. Optimization of the placement of power supplies in the formation of a rational configuration of power supply systems // Electricity, 2012, № 10

7. Svezhentseva O.V. Development and testing of the genetic algorithm for the optimal placement of power sources in the electrical distribution network. Bulletin of Irkutsk State Technical University, 2012, № 4

8. Voropai N. I., Svezhentseva O.V. Optimization of supply source allocation in the problem of rational configuration of electricity supply system // IEEE ISGT Europe Int. lonf., Berlin, Germany, October $14-17$, 2012.

9. Svezhentseva, O. V. Modeling of an electric network of a loop structure // All-Russian scientific-practical 
conference "Increasing the efficiency of production and use of energy in Siberia", Irkutsk: ISTU, 2009.

10. Svezhentseva, O. V. Construction of an optimal route of a power transmission line using optimization algorithms on graphs // All-Russian scientific and practical conference "Improving the efficiency of production and use of energy in Siberia", Irkutsk: IrGTU, 2011. 